\title{
Asymptomatic bacteriuria in postmenopausal women with diabetes mellitus
}

\author{
George Kasyan ${ }^{1}$, Tatiana Y. Berketova², Anton K. Rogozin³ ${ }^{3}$ Dmitry Y. Pushkar ${ }^{1}$ \\ ${ }^{1}$ Urology Department of Moscow State University of Medicine and Dentistry, Moscow, Russian Federation \\ ${ }^{2}$ Endocrinology Department of First Moscow State University of Medicine, Moscow, Russian Federation \\ ${ }^{3}$ Pirogov Russian National Research Medical University, Department of Endocrinology and Diabetology, Moscow, Russian Federation
}

Article history

Submitted: April 2, 2013

Accepted: May 1, 2013

Correspondence

George Kasyan

Urology Department of

Moscow State University

of Medicine and Dentistry

15/69, Mosfilmovskaya

Street

119330 Moscow,

Russian Federation

phone: +9154643318

g.kasyan@gmail.com
Introduction. An evaluation of efficacy of the management of urinary tract infections by using local forms of Estriol in postmenopausal women with type II diabetes and asymptomatic bacteriuria. Material and methods. The study was conducted in two stages. The first stage: a prospective crosssectional study to identify patients with asymptomatic bacteriuria. During this stage, 414 postmenopausal women with type II diabetes, but without clinical symptoms of urinary tract infection, were investigated. In the second stage, women with asymptomatic bacteriuria (87 women) were randomized to two groups: the first group was the main group receiving $0.5 \mathrm{mg}$ of Estriol as a vaginal cream, the second group was the control group. The study lasted 12 months.

Results. After 12 months of the study, asymptomatic bacteriuria was revealed in $19.4 \%$ of women in the group 1 and $68.4 \%$ of women in the group $2(p<0.001)$, and symptomatic urinary tract infection in $8.3 \%$ of women in the group 1 and $18.4 \%$ of women in the group $2(p<0.001)$. There was no connection revealed between asymptomatic bacteriuria and $\mathrm{HBA} 1 \mathrm{c}$. Using Estriol in group 1 led to an increase in $\mathrm{VHI}$, the appearance of lactobacilli in the vaginal smear, and the decrease of symptom frequency in atrophic vaginitis. In group 2, there were no significant changes revealed.

Conclusions. Usage of local forms of Estriol effectively prevents and decreases the frequency of asymptomatic bacteriuria and urinary tract infection in postmenopausal women suffering with diabetes mellitus.

Key Words: asymptomatic bacteriuria 〈> urinary tract infections 〈〉diabetes mellitus 〈〉 postmenopause

\section{INTRODUCTION}

The necessity to treat asymptomatic bacteriuria $(\mathrm{AB})$ in women with type II diabetes is a problem, which could be called unsolved since the analyses of current data on usage of traditional treatment strategy. Particularly antibacterial therapy shows limited efficacy in such patients [1].

The importance of that problem is determined, first of all, both by high prevalence of $\mathrm{AB}$ among women $[2,3]$, as well as by high prevalence of type II diabetes among postmenopausal women [4]. According to some authors, the necessity to treat $\mathrm{AB}$ in patients with type II diabetes is related to the risk of the development of upper and lower urinary tract infections (UTI) [4, 5], consequently, taking into consideration the seriousness of potential risks, the principles of treatment are the same as in case of symptomatic urinary tract infections - antibacterial therapy. However, in spite of the current data on development of complications in $\mathrm{AB}$, the need to treat $\mathrm{AB}$ for prevention of UTI continues to be actively discussed.

There is a current opinion in the literature that prescription of antibiotics in $\mathrm{AB}$ makes sense only in the case of additional factors of UTI development, such as a need for catheterization and urinary tract structural anomalies. In other cases, as it was shown in 
the large number of studies, an antimicrobial treatment in $\mathrm{AB}$ does not lead to decreasing of the frequency of recurrences and re-infections.

Thus, the study conducted by Harding G. [6], where the effectiveness of antimicrobial therapy in women with $\mathrm{AB}$ and type II diabetes were investigated, showed that after 4 weeks of a 6 -week antimicrobial regimen, $\mathrm{AB}$ continued in $20 \%$ of patients with diabetes in the group receiving antimicrobial therapy and in $78 \%$ of patients in placebo group.

At 27-month follow-up, there was minimum one episode of urinary tract infection in $40 \%$ of women in placebo group and in $42 \%$ of women receiving antibiotics [7]. The retrospective analysis of studies conducted during period from 1967 to April 2003 showed no evidence of effectiveness of antibiotic use in $\mathrm{AB}$ [8]. A fundamentally different approach to prevent recurrent UTI in postmenopausal women is an estrogen regimen. Age-related changes in tissues of the urogenital tract, connected with the development of deficiency of sex hormones after menopause, play a leading role in development of urogenital problems. Inefficiency of antimicrobial therapy in postmenopausal women with diabetes probably relates to the underestimated progressive atrophy of the vaginal mucosa and urinary tract. Studies of the risk factors of $\mathrm{AB}$ development in women with diabetes show a significant correlation between age and frequency of bacteriuria.

There were no studies on the use of local forms of hormonal therapy in women with type II diabetes for treatment of $\mathrm{AB}$ and prevention of lower urinary tract symptoms (LUTS).

Aim of the current study was an assessment of the possibility of prevention of urinary tract infections by using the local forms of Estriolin in postmenopausal women with diabetes and $\mathrm{AB}$.

\section{MATERIALS AND METHODS}

According to the aims, there are two stages emphasized in the study. The first stage - a prospective cross-sectional study revealing $\mathrm{AB}$ cases. The second stage - randomized case-control prospective cohort study for assessment of the effectiveness and eligibility of the use of local forms of Estriol for treatment of $\mathrm{AB}$ and for prevention of symptomatic forms of UTI. Postmenopausal women with type II diabetes, normoglycemic, without symptomatic signs of UTI participated in the study. The quantitative count of $\geq 10^{5} \mathrm{cfu} / \mathrm{ml}$ of an organism in a voided urine specimen without urinary tract symptoms was accepted as $\mathrm{AB}[9]$.

Inclusion criteria were limited to:

- Diabetes type II
- Normoglycemia

- Postmenopausal period

Exclusion criteria were limited to:

- Diabetes type 1

- Significant decompensation of diabetes

$\left.\left(\mathrm{H}_{\mathrm{B}} \mathrm{A} 1_{\mathrm{C}} \geq 10 \%\right)\right)$ and lack of self-control skills

- Glycosuria at time of the study

- Symptomatic UTI

- Autonomic diabetic polyneuropathy

- Estrogen dependent tumors

- Taking replacement hormonal therapy by sex steroids

- Anatomical defects of the genitourinary system

- Chronic kidney and liver failure

The study was performed after obtaining the consent from the patients and approval of the local Ethics Committee.

At the first stage, after assessing the compliance to inclusion-exclusion criteria, all patients undergone common clinical and microbiological analyses of the urine to reveal $\mathrm{AB}$.

Bacteriological investigation of urine was carried out by standard method accepted in the clinic: midstream urine, taken after hygienic processing of the vulva, was planted by dimensional loop $(0.01 \mathrm{ml})$ on Petri dishes with blood agar and Levin's medium (Bekton-Dikinson, USA). After incubation at $35^{\circ} \mathrm{C}$ over 18 hours, the quantity of microbes per $1 \mathrm{ml}$ of urine was recalculated based on the number of grown colonies and volume of seeded fluid. Identification and sensitivity of the microbes to antibiotics were carried out on automated microbiological system FENIX 100 (Bekton Dikinson, USA)

In some bacilli, the testing on sensitivity was carried out using a disk-diffusion method in accordance with current standards.

The diagnoses of $\mathrm{AB}$ confirmed detecting the same strain of bacilli in the amount of $10^{5}(100,000)$ and more CFU/ml (colony-forming units) in two consecutive urine analyses.

After confirming the diagnoses of $\mathrm{AB}$, screened women were consistently randomized to two groups by block randomization technique. The treatment method was chosen according to admission date and was changed on a weekly basis.

Women taking local estriol as a vaginal cream containing $0.5 \mathrm{mg}$ of estriol daily at night during three weeks with subsequent transition to the maintenance therapy - twice a week during 12 months were included into the first (main) group.

Women with natural follow of $\mathrm{AB}$ without taking any preventive therapy were included into the second (control) group.

At the second stage of the study, screened women underwent gynecological investigation; colposcopy; 
calculation of the index of vaginal health: elasticity, transudate, $\mathrm{pH}$, epithelial integrity, humidity [7]; mirror examination of the cervix; and Pappanikolau's smear from the upper third of the vaginal wall. Studying of the vaginal culture included complex investigation of the vaginal smear, which was based on culture and microscopy of the vaginal smear colored by Gram stain. Vaginal secretion on the swab, brought to the laboratory in a tube with transport medium, was plated to the special mediums: blood agar, Levin' media, mannitol-salt agar (Staphylococci), bilious-esculin agar (Enterococci), Sabouraud's agar with chloramphenicol and gentamicin (Fungi). All mediums are manufactured by Bekton- Dikinson, USA.

At the beginning and after 3, 6, and 12 months of therapy, urine common and microbiological analyses, as well as bacteriological analysis of vaginal microflora were conducted, the degree of atrophy of vaginal mucosa was assessed, the vaginal health index as well as the vaginal $\mathrm{pH}$ were measured. Patients'complaints and the degree compensation of type II diabetes by the level of HbA1c were assessed. Upon identifying the symptomatic urinary tract infections, the antimicrobial therapy (pefloxacin, 800 $\mathrm{mg}$ /day during 7 days) was prescribed to the patients during the study; in case of nonspecific vaginitis, $\mathrm{Ni}$ furatel suppositories were used; in case of bacterial vaginosis, clindamycin cream, and vaginal candidiasis was managed by fluconazole. After completion of the therapy the patients continued to be studied.

\section{Statistical analysis}

Statistical analysis of the results was done using statistical package Epi Info Software 3.4.3.

Indicators, expressed by quantified continuous variables, were presented as means \pm standard deviation $(\mathrm{M} \pm \mathrm{SD})$. Analysis of distribution of indicators' values for compliance with the law of normal distribution was carried out using a test Shapiro-Wilk.
Statistical significance assessment of intra- and inter-group differences of quantitative indicators was carried out using Student's t-criterion, MannWhitney U-criterion and criterion of Wilcoxon McNemar.

A comparison of quality indicators in independent collections was produced by $\chi 2$ criterion and Fisher's exact criterion. To describe the relationship between variables, Spearman rank correlation coefficient $\left(r_{s}\right)$ was calculated. Level of statistical significance was accepted at $\mathrm{p} \leq 0.05$.

\section{RESULTS}

At the first stage of the study during the screening on $\mathrm{AB}, 414$ women without symptomatic UTI were examined. At once collected microbiological analysis of urine, bacteriuria in the amount of $10^{5}$ or more CFU / ml was detected in 135 (32.6\%) of women.

With repetition of the microbiological analysis of urine in patients with once detected bacteriuria after 7-10 days, 41 (9.9\%) women had received a normal urinalysis. Between the first and second urine analysis the patients did not receive antibiotics, but were re-instructed on technique of urine collection. After two series of urine analysis, with an interval of 7-10 days, $\mathrm{AB}$ was diagnosed in $94(22.7 \%)$ of the 414 patients.

In the second phase of the study, seven of 94 patients were unable to continue the study because of discrepancy of inclusion-exclusion criteria. The 87 women who were able to continue the study were randomly assigned to two groups.

Later, during the study, 9 patients were excluded from the group I and five patients were excluded from group II. The reason for premature exception was violation of the study protocol. Thirty-four patients in the main group and 39 patients in the control group managed fully to complete the study, going through all its stages. Follow-up visits were carried out at 3, 6, and 12 months from the start of the study. However, in this

Table 1. Characteristics of patients included in the study

\begin{tabular}{|c|c|c|c|}
\hline Indicator & Group I $(n=43), n(\%$ or $M \pm S D)$ & Group II $(n=44), n(\%$ or $M \pm S D)$ & $\mathrm{p}$ \\
\hline Age (years) $\mathrm{M} \pm \mathrm{SD}$ & $59.7 \pm 5.7$ & $60.2 \pm 5.3$ & 0.683 \\
\hline Duration of diabetes (years) $M \pm S D$ & $8.7 \pm 6.8$ & $8.8 \pm 6.0$ & 0.997 \\
\hline Duration of menopause (years) $M \pm S D$ & $10.1 \pm 5.3$ & $10.7 \pm 5.3$ & 0.591 \\
\hline Level of $\mathrm{HbA} 1 \mathrm{c} . \mathrm{M} \pm \mathrm{SD}$ & $8.61 \pm 2.03$ & $8.58 \pm 1.99$ & 0.942 \\
\hline Arterial hypertension & $86.0 \%$ & 88.6 & 0.967 \\
\hline Diabetic retinopathy & 37.2 & 36.4 & 1.000 \\
\hline Diabetic nephropathy & 46.5 & 47.7 & 1.000 \\
\hline Diabetic polyneuropathy & 76.7 & 77.3 & 1.000 \\
\hline
\end{tabular}


article, the initial and final results are mainly represented. Both groups of patients were matched by age, duration of diabetes and menopause, as well as by the incidence of arterial hypertension, diabetic retinopathy, nephropathy, and peripheral neuropathy. Clinical characteristics of patients are presented in Table 1.

The initial level of glycated hemoglobin did not differ in both groups and was $8.61 \pm 2.03$ in the main group and $8.58 \pm 1.99$ in the control group. However, at the beginning of the study, all women had achieved normoglycemia: fasting glucose was until $6 \mathrm{mmol} / \mathrm{l}$, postprandial - until $8 \mathrm{mmol} / \mathrm{l}$. Characteristics of the initial glucose-lowering therapy is shown in table 2 , with no statistically significant differences revealed in the methods of glucose-lowering therapy at the time of inclusion into the study. Later, during the study, the principle of glucose-lowering therapy did not fundamentally change; the doses of hypoglycemic agents based on self-control results presented by patients at their visits were corrected.

At the beginning of the study, all patients were diagnosed with $A B$, but clinical forms of UTI were exclud-

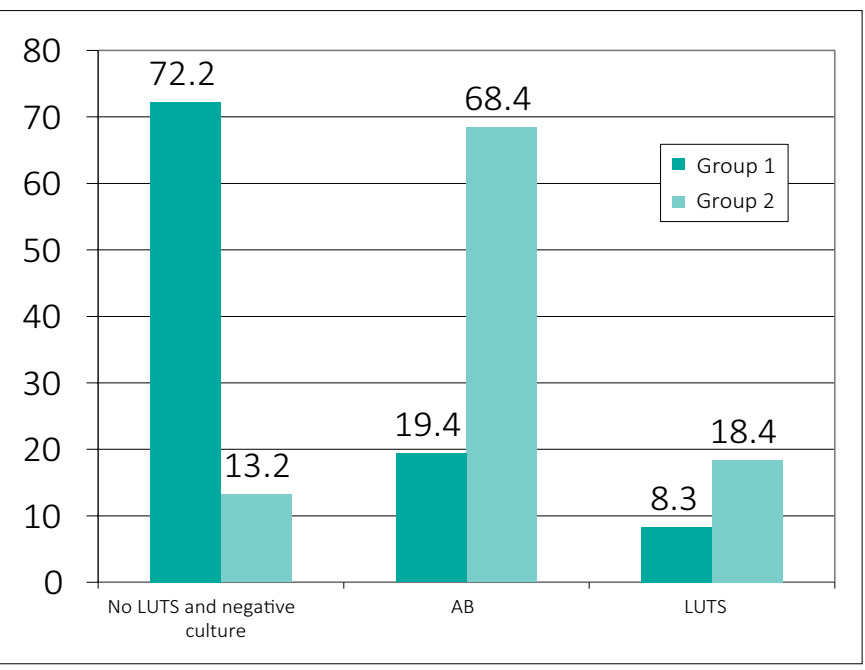

Figure 1. The incidence of $A B$ and UTI after 12 months from the start of the study.

Table 2. Initial characteristics of glucose-lowering therapy and the state of carbohydrate metabolism

\begin{tabular}{lccc}
\hline Indicator/Treatment & $\begin{array}{c}\text { Main group } \\
(\mathrm{n}=43)\end{array}$ & $\begin{array}{c}\text { Control group } \\
(\mathrm{n}=44)\end{array}$ & $\mathrm{p}$ \\
\hline HbA1c. \% & $8.61 \pm 2.03$ & $8.58 \pm 1.99$ & 0.942 \\
\hline Sulfonylurea & 5 & 6 & 0.854 \\
\hline Sulfonylurea + metformin & 9 & 12 & 0.854 \\
\hdashline Combined therapy & 18 & 15 & 0.854 \\
\hdashline Insulin & 11 & 11 & 1.000 \\
\hline
\end{tabular}

Table 3. Relations between levels of $\mathrm{H}_{8} \mathrm{~A} 1 \mathrm{c}$ and development of $A B$ and symptomatic forms of UTI after 12 months

\begin{tabular}{lccc}
\hline Indicator & $\begin{array}{c}\text { Main group } \\
(\mathrm{n}=34)\end{array}$ & $\begin{array}{c}\text { Control group } \\
(\mathrm{n}=39)\end{array}$ & $\mathrm{p}$ \\
\hline Mean HBA1c in the groups & $7.07 \pm 1.2$ & $6.9 \pm 1.23$ & 0.790 \\
\hdashline No of patients (\%) with & $13(36.1 \%)$ & $12(31.6 \%)$ & 0.807 \\
HBA1c $\geq 7.5 \%$ & $\ldots(19.4 \%)$ & $26(68.4 \%)$ & $<0.001$ \\
\hline No of patients (\%) with AB & $7 . . .$. \\
\hline No of patients (\%) with UTI & $3(8.3 \%)$ & $7(18.4 \%)$ & $<0.001$ \\
\hline
\end{tabular}

ed. After 12 months of the beginning of the treatment, a decrease of the frequency of $\mathrm{AB}$ to $19.4 \%$ and symptomatic UTI to $8.3 \%$ was detected in patients of the main group. In the control group, $\mathrm{AB}$ was detected in $68.4 \%$ of patients, and symptomatic UTI in $18.4 \%$ (p $<0.001$ ) (Figure 1). However, during the study we did not reveal any relations between level of $\mathrm{H}_{\mathrm{B}} \mathrm{A} 1_{\mathrm{C}}$ and frequency of $\mathrm{AB}$. At the end of the study $\mathrm{H}_{\mathrm{B}} \mathrm{A} 1_{\mathrm{C}}$ was $\geq 7.5 \%$ in $13(36.1 \%)$ of patients in main group, $\mathrm{AB}$ was revealed in $7(19.4 \%)$ of patients, $\mathrm{AB}$ was diagnosed in $26(68.4 \%)$ ( $p<0.001)$ of patients in control group in spite of the fact that $\mathrm{H}_{\mathrm{B}} \mathrm{A} 1_{\mathrm{C}}$ at the $9^{\text {th }}$ months was $\geq 7.5 \%$ in $12(31.6 \%)$ of patients (Table 3 ).

There were no differences in bacterial composition of urine in women of both groups. E.coli was revealed in $62.5 \%$ of patients in the main group, staphylococci in $10 \%$, streptococci in $12.5 \%$, and microbial associations in $15 \%$ of patients. In the control group, mentioned microorganisms were detected in $64.1 \%$, $12.1 \%, 11.8 \%$, and $12 \%$ of patients, respectively.

We studied the peculiarities of vaginal microecology in women with $\mathrm{AB}$ (Table 4). The atrophic vaginitis, characterized by disappearance of lactobacilli or sharp decline in their titers in the absence of massive colonization by opportunistic microorganisms and the inflammatory component, was revealed in the majority of patients in both groups (32.6\% of patients in the main and $36.4 \%$ in the control group). The status of "conditional normocenosis", characterized by decreasing the concentrations of lactobacilli, increasing titers of opportunistic pathogens and by the absence of inflammation, was found with similar frequency (27.9\% in the main group and $25.0 \%$ in the control group). Bacterial vaginosis were revealed in $14 \%$ of patients of the main group and in $9.1 \%$ of the patients in the control group. Nonspecific vaginitis, characterized by mild inflammatory response (up to 15 white blood cells per field) and small number of homogeneous microflora, were revealed in $18.6 \%$ of patients in the main group and in $22.7 \%$ of patients in the control group. Beside that, the vaginal candidiasis was diagnosed in $7 \%$ of patients in the main group and in $6.8 \%$ of patients in the control group. 
Table 4. Data of vaginal culture tests' results before and after treatment

\begin{tabular}{|c|c|c|c|c|c|c|}
\hline & \multicolumn{2}{|c|}{ Main group } & \multirow[b]{2}{*}{$\mathrm{p}$} & \multicolumn{2}{|c|}{ Control group } & \multirow[b]{2}{*}{$\mathrm{p}$} \\
\hline & baseline & $\begin{array}{l}\text { after } 12 \\
\text { months }\end{array}$ & & baseline & $\begin{array}{l}\text { after } 12 \\
\text { months }\end{array}$ & \\
\hline Mean $\mathrm{H}_{\mathrm{BA}} 1 \mathrm{c} \%$ & $8.61 \pm 2.03$ & $7.07 \pm 1.2$ & $<0.001$ & $8.58 \pm 1.99$ & $6.9 \pm 1.23$ & $<0.001$ \\
\hline No. of patients (\%) with atrophic colitis & $32.6 \%$ & $9.1 \%$ & \multirow{4}{*}{$<0.001$} & $36.4 \%$ & $55.3 \%$ & \multirow{5}{*}{$>0.05$} \\
\hline No. of patients (\%) with normocenosis & $27.9 \%$ & $6.1 \%$ & & $25.0 \%$ & $21.1 \%$ & \\
\hline No. of patients (\%) with bacterial vaginosis & $14.0 \%$ & 0 & & $9.1 \%$ & $2.6 \%$ & \\
\hline No. of patients (\%) with nonspecific vaginitis & $18.6 \%$ & $3.0 \%$ & & $22.7 \%$ & $10.5 \%$ & \\
\hline No. of patients (\%) with candidiasis & $7.0 \%$ & $6.1 \%$ & $<0.05$ & $6.8 \%$ & $7.9 \%$ & \\
\hline
\end{tabular}

Bacterial composition of the vagina also did not differ in both groups. E. Coli dominated mainly and were found in $71 \%$ of patients in the main group and $78 \%$ of the patients in the control group.

In our study, special attention was paid to the presence of Lactobacilli, which have protective role of the vagina competing with pathogens whose level is more than $105 \mathrm{CFU} / \mathrm{ml}$ and can reach $10^{8}-10^{9} \mathrm{CFU} /$ $\mathrm{ml}$ in reproductive age women. Initially Lactobacilli at the amount of $>10^{5} \mathrm{CFU} / \mathrm{ml}$ were detected in 20 (46.5\%) patients in the main group and in 22 (50\%) patients in the control group ( $\mathrm{p}>0.05)$.

After 12 months from the beginning of the treatment, a normal amount of vaginal Lactobacilli was detected in the remaining patients of the main group - $35(97.2 \%)$ - and in $17(44.7 \%)$ patients of the control group $(\mathrm{p}<0.001)$.

The vaginal health index (VHI) is used to reveal the severity of atrophic processes in vagina and checked regularly in patients receiving treatment with local forms of hormone therapy. In the main

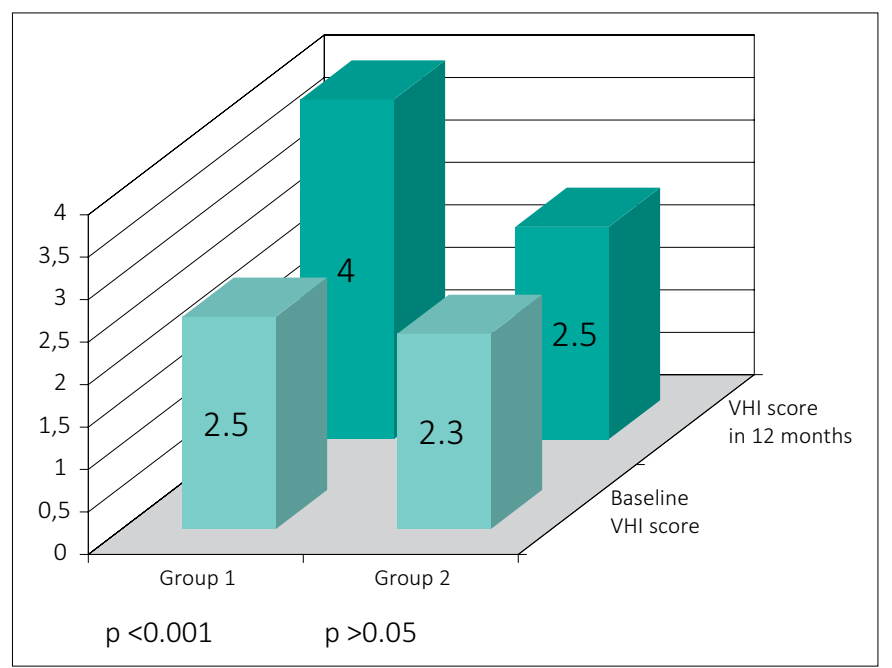

Figure 2. Changes of vaginal culture at baseline and after 12 months. group of patients prior to the treatment it was 2.85 , after 12 months it was $4.3(\mathrm{p}<0.001)$; in the patients of the control group it remained the same -2.79 and 2.71 after 12 months, respectively ( $p$ $>0.05$ ) (Figure 2).

During the study the nature of the complaints and their severity were analyzed. At the beginning and the end of the study patients were asked to answer the question, whether they notice any unpleasant, disturbing sensation in the vagina. Thus, at the beginning of the study, vaginal dryness was noted in $22(51.2 \%)$, itching of the vulva in $14(38.6 \%)$, dyspareunia in $21(48.8 \%)$ patients of the main group and in $20(45.5 \%), 17(32.6 \%)$ and $24(54.5 \%)$ patients of the control group, respectively. After 12 months, in patients of the first group, the frequency of detected signs of atrophic vaginitis decreased: thus, vaginal dryness persisted in two $(5.7 \%)(\mathrm{p}<0.001)$, itching of the vulva in four $(11.1 \%)(\mathrm{p}<0,05)$, and dyspareunia in six $(16.7 \%)(p>0.05)$ patients, whereas in patients of the second group, significant changes were not noted: vaginal dryness was found in $19(50.0 \%)$ ( $>0.05)$, itching of the vulva in $18(47.4 \%)$ ( $\mathrm{p}>0.05)$, and dyspareunia in $17(44.7 \%)$ ( $\mathrm{p}>0.05)$ patients (Figure 3).

\section{DISCUSSIONS}

One of the major non-specific complications in diabetic patients is the urinary tract infection [10]. According to some authors, the frequency of urinary tract infections in patients with diabetes reaches $40 \%$, which is almost three times higher than in the general population [11]. Urinary tract infections often complicate the course of diabetes and associate with a high risk of rapid deterioration of renal function, especially in patients with clinical signs of diabetic nephropathy and arterial hypertension. In our study, during the screening, we diagnosed $\mathrm{AB}$ in $22.7 \%$ of patients with type II diabetes. Results of our study also showed that in $68.4 \%$ of patients of 


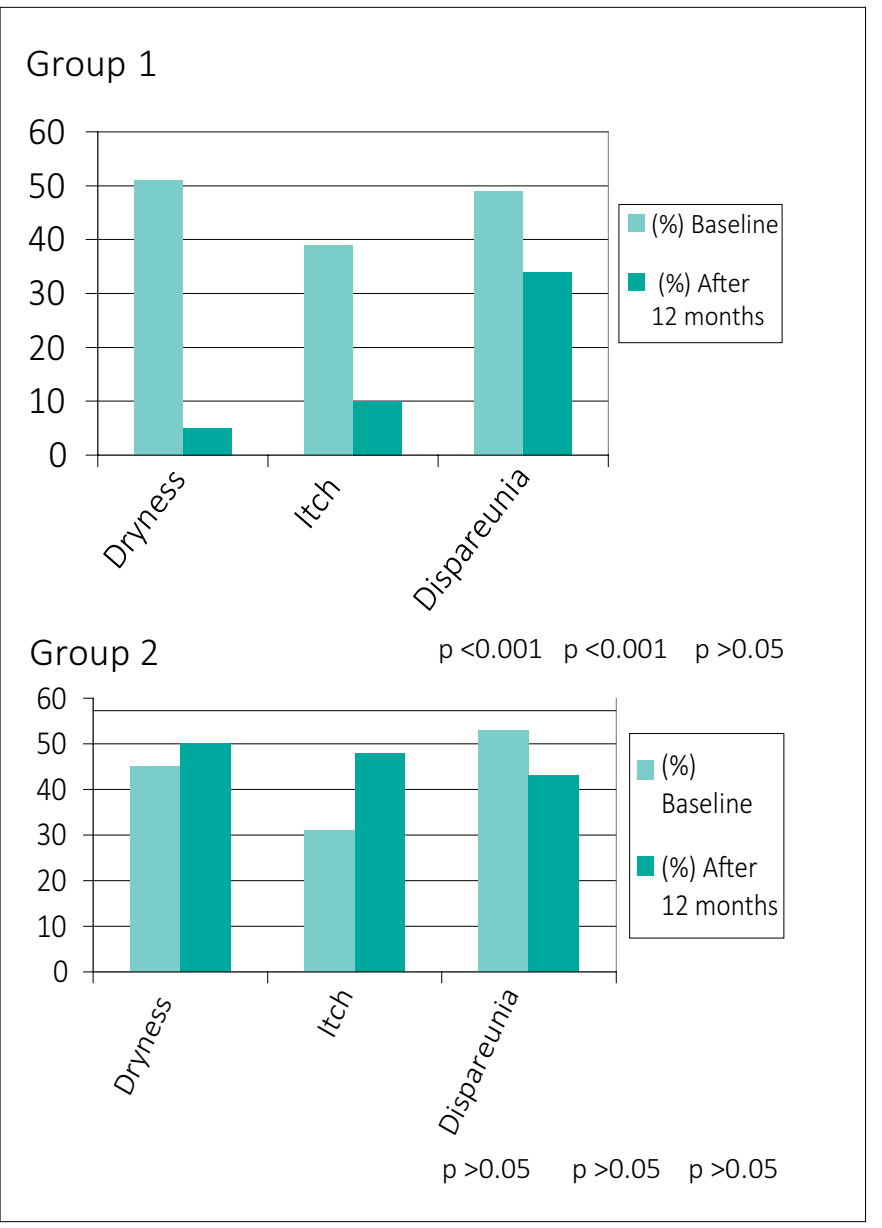

Figure 3. Prevalence of symptoms of atrophic vaginitis at baseline and after 12 months.

the control group not receiving any treatment, after 12 months of follow-up the $\mathrm{AB}$ remained the same, and moreover, in $18.4 \%$ of patients in this group, clinical forms of UTI were diagnosed. At the same time, we did not observe a significant difference in the incidence of $\mathrm{AB}$ in patients with different levels of $\mathrm{H}_{\mathrm{B}} \mathrm{A} 1_{\mathrm{C}}$ : $\mathrm{AB}$ developed with almost equal frequency in patients with $\mathrm{H}_{\mathrm{B}} \mathrm{A} 1_{\mathrm{C}}$ both less than $7.5 \%$ and greater than $7.5 \%$. Despite that, after 12 months from the start of the study, we observed a significant reduction in the incidence of $\mathrm{AB}$ in patients receiving local estriol (group 1). Undoubtedly, proper compensation of diabetes plays a leading role in the prevention and treatment of UTIs. However, giving attention to our results, on can suppose that decompensation of diabetes is not the only cause of $\mathrm{AB}$ and clinically evident UTI in postmenopausal women with diabetes.

Increased frequency of UTI with age in women is associated with the development of significant atrophic changes of the vaginal mucosa and urethra in the postmenopausal period with estrogen deficiency and changes of the vaginal flora. During the objective examination of patients, we have identified changes that are typical for epithelial atrophy associated with estrogen deficiency in postmenopausal women, namely: high $\mathrm{pH}$ and low VHI.

Also, our study was undertaken to examine the bacterial state of the vagina in women with $\mathrm{AB}$ and diabetes and to clarify the influence of local forms of Estriolon on the vaginal microflora in postmenopausal women with diabetes. According to some authors, the causative agent in the majority of cases of urinary tract infections in patients with diabetes is E.coli, while other less common causes are gramnegative bacteria, staphylococci, and enterococci. [1, 3]. Our results revealed mainly E.coli during vaginal cultural examination and microbiological examination of urine, fully compatible with these procedures.

Treatment with the local forms of estriol led to the restoration of mucosal barrier of the vaginal wall, which was confirmed by an increase of VHI to 4.3, and restoration of vaginal microecology. Based on this, we noted an effective reduction in $\mathrm{AB}$ incidence in women of the main group, which in turn reduced the risk of symptomatic forms of UTI.

Despite the high efficiency of the local estriols, after 12 months, seven patients from the main group remained $\mathrm{AB}$ and three patients developed clinical forms of UTI. This result is probably due to the fact that in patients with diabetes, population-wide factors contributing to the development of urinary tract infection are combined with specific risk factors inherent in diabetes and its complications: glycosuria, neuropathic bladder, and decreased immune defense.

A small reduction in frequency of $\mathrm{AB}$ occurred in the control group. This can be explained by the fact that, according to the study protocol, all women, regardless of whether or not they administered estriol, in case of development of clinical forms of UTI during the study, received antibiotic therapy, and in case of development of nonspecific vaginitis or bacterial vaginosis they receive local intravaginal antibiotic treatment. Thus, the vaginal flora was under constant supervision and, if necessary, corrected, but without use of systemic antibiotic therapy. Such tactics of the patient's treatment was close to the option of observation, which may also be in actual practice, in case of careful self-attention of woman and understanding the need for regular visits to the doctor. In case, if the vaginal microflora is not tracked, single sanitation of the vagina with subsequent reduction of the titer of bacteria in the urine, may be an intermediate stage and the situation is likely to return 
to the initial situation, as we have seen in most patients of the control group.

Treatment with estriol also led to significant decrease of dryness and itching of the vagina, which improves the quality of life. The findings on the effectiveness of use of the local forms of estriol are interesting since they expand our understanding of the therapeutic potential of that drug; in addition to the positive impact in case of atrophic vaginitis, the ability to treat $\mathrm{AB}$ and therefore, to prevent symptomatic forms of UTI in both postmenopausal patients with diabetes and those in the general population. This preventive approach can become an alternative to the prolonged use of antibiotics.

\section{CONCLUSIONS}

Asymptomatic bacteriuria in postmenopausal women with type II diabetes is a risk factor for development of symptomatic UTI. The cause of UTI in postmenopausal women with diabetes is not only decompensated diabetes, but also hormonal changes during menopause. The local forms of estriol are effective in postmenopausal women with diabetes as a treatment of $\mathrm{AB}$ and as a prevention of clinically symptomatic urinary tract infections. Therapy with local forms of estriol restores the protective microbial barrier of the vaginal wall, increasing the VHI to values specific to women of reproductive age.

\section{References}

1. Forland M, Thormas W, Shelokov A. Urinary tract infections in patients with diabetes mellitus: Studies on antibody coating of bacteria. J Am Med Ass. 1977; 238: 1924-1926

2. Harding G, Zhanel G, Nicolle L, Cheang M. Antimicrobial treatment in diabetic women with asymptomatic bacteriuria. N Engl J Med. 2002; 347: 1576-1583.

3. Zhanel GG,Nicolle LE, Harding GK. Prevalence of asymptomatic bacteriuria and associated host factors in women with diabetes mellitus. The Manitoba Diabetic Urinary Infection Study Group. Clin Infect Dis. 1995; 21: 316-322.

4. Geerlings S, Stolk R, Camps M, Netten PM, Collet JT, Schneeberger PM, Hoepelman AI.
Consequences of asymptomatic bacteriuria in women with diabetes mellitus. Arch Intern Med. 2001; 161: 1421-1427.

5. Balasoiu D, Kessel KC, Kats-Renaud HJ, Collet TJ, Hoepelman Al. Granulocyte function in women with diabetes and asymptomatic bacteriuria. Diabetes Care. 1997; 20: 392-395.

6. Stein G, Funfstuck R. Asymptomatic bacteriuria - what to do. Nephrol Dial Transplant. 1999; 14: 1618-1617.

7. Merta M, Rysavá R, Tesar V. Urinary tract infection in patients with diabetes mellitus. Vnitr Lek. 2006; 52: 423-425.

8. Nicolle LE, Bradley S, Colgan R, Rice JC, Schaeffer A, and Hooton TM. Infectious
Diseases Society of America guidelines for the diagnosis and treatment of asymptomatic bacteriuria in adults. Clin Infect Dis. 2005. 40: 643-654.

9. Ooi ST, Frazee LA, Gardner WG. Management of asymptomatic bacteriuria in patients with diabetes mellitus. Ann Pharmacother. 2004; 38: 490-493.

10. Geerlings SE, Stolk RP, Camps MJL, Netten PM, Hoekstra JBL, Bouter KP, et al. Prevalence and risk factors for asymptomatic bacteriuria in women with diabetes mellitus. ICAAC 1999; abs 607.

11. Kasinath BS, Musais SK, Spargo BH, Katz Al. Non-diabetic renal disease in patients with diabetes mellitus. Am J Med. 1983; 75: 613-617. 